\title{
Erratum to: Part II: Effect of high energy proton beam fluence on the electrical studies of lithium gallium phosphate glass electrolyte doped with selenium ions
}

\author{
Ch. V. Koti Reddy • R. Balaji Rao - K. Chandra Mouli • \\ D. V. Rama Koti Reddy • K. B. S. Krishna
}

Published online: 15 March 2013

(C) Springer-Verlag Berlin Heidelberg 2013

\section{Erratum to: IONICS \\ DOI 10.1007/s11581-012-0765-1}

The term "Part II:" in the title of the paper should be omitted since there is no reference given to any preceding "Part I" paper. The correct title should therefore be

Electrical conductivity, electrical modulus and scaling studies of $\mathrm{Li}_{2} \mathrm{O}-\mathrm{Ga}_{2} \mathrm{O}_{3}-\mathrm{P}_{2} \mathrm{O}_{5}$ glass electrolyte doped with of selenium ions

by Ch. V. Koti Reddy. R. Balaji Rao. K. Chandra Mouli. D. V. Rama Koti Reddy. K. B. S. Krishna
The authors see in this contribution a continuation of their previously published work

Electrical conductivity, electrical modulus, and scaling studies of $\mathrm{Li}_{2} \mathrm{O}-\mathrm{Ga}_{2} \mathrm{O}_{3}-\mathrm{P}_{2} \mathrm{O}_{5}$ glass electrolyte doped with of selenium ions

by Ch. V. Koti Reddy. R. Balaji Rao. K. Chandra Mouli. D. V. Rama Koti Reddy. K. Veera Bhadra Rao, published in IONICS (2012) Vol. 18 pages 65-73. This work has been cited as Ref. [16].

The online version of the original article can be found at http://dx.doi.org/ 10.1007/s11581-012-0765-1.

C. V. K. Reddy $\cdot$ K. C. Mouli

Department of Engineering Physics, A.U. College of Engineering,

Visakhapatnam, Andhra Pradesh, India

D. V. R. K. Reddy

Department of Instrument Technology, A.U. College of Engineering,

Visakhapatnam, Andhra Pradesh, India

R. B. Rao $(\bowtie) \cdot$ K. B. S. Krishna

Department of Physics, GITAM University,

Hyderabad Campus, Hyderabad, India

e-mail: ravuri3091@yahoo.co.in 